\title{
p19 detected in the rat retina and pineal gland is a guanylyl cyclase-activating protein $\left(\right.$ GCAP) ${ }^{\star \star}$
}

\author{
Agnieszka Dejda ${ }^{1}$, Izabela Matczak ${ }^{1}$ and Wojciech A. Gorczyca ${ }^{1,2 \bowtie}$ \\ ${ }^{1}$ Department of Biogenic Amines, Polish Academy of Sciences, Eódz, Poland; ${ }^{2}$ Laboratory of \\ Signaling Proteins, L. Hirszfeld Institute of Immunology and Experimental Therapy, Polish \\ Academy of Sciences, Wroctaw, Poland
}

Received: 19 November, 2002; revised: 30 November, 2002; accepted: 2 December, 2002

Key words: calcium-binding proteins, guanylyl cyclase-activating proteins, guanylyl cyclase, retina, pineal gland, rat

\begin{abstract}
The $\mathrm{Ca}^{2+}$-dependent activation of retina-specific guanylyl cyclase (retGC) is mediated by guanylyl cyclase-activating proteins (GCAPs). Here we report for the first time detection of a $19 \mathrm{kDa}$ protein (p19) with GCAP properties in extracts of rat retina and pineal gland. Both extracts stimulate synthesis of cGMP in rod outer segment (ROS) membranes at low $(30 \mathrm{nM})$ but not at high $(1 \mu \mathrm{M})$ concentrations of $\mathrm{Ca}^{2+}$. At low $\mathrm{Ca}^{2+}$, immunoaffinity purified p19 activates guanylyl cyclase(s) in bovine ROS and rat retinal membranes. Moreover, $p 19$ is recognized by antibodies against bovine GCAP1 and, similarly to other GCAPs, exhibits a $\mathrm{Ca}^{2+}$-dependent electrophoretic mobility shift.
\end{abstract}

Molecules of cyclic GMP (cGMP) interact directly with cationic channels located in the plasma membrane of the outer segments of retinal photoreceptor cells and keep the chan- nels open. Light triggers a cascade of biochemical events which lead to the hydrolysis of cGMP by photoreceptor-specific phosphodiesterase (PDE6) and closure of the channels

\footnotetext{
ॠ Part of this work was presented at the 8th Polish Conference on Cell Biology, Wrocław, Poland, September, 2002.

${ }^{*}$ This work was supported in part by the State Committee for Scientific Research (KBN, Poland) grants No 6 P04A 05820 to A.D. and 6 P04C 07020 to I.M.

${ }^{\otimes}$ Corresponding author: Wojciech A. Gorczyca, Laboratory of Signaling Proteins, L. Hirszfeld Institute of Immunology and Experimental Therapy, R. Weigla 12, 53-114 Wrocław, Poland; tel.: (48 71) 337 1172; fax: (48 71) 337 1382; e-mail: gorczyca@immuno.iitd.pan.wroc.pl

Abbreviations: GC, guanylyl cyclase; GCAP, guanylyl cyclase-activating protein; IBMX, 3-isobutyl-1-methylxanthine; NCS, neuronal calcium sensors; retGC; retina-specific guanylyl cyclase; ROS, rod outer segments.
} 
(reviewed by Gorczyca 1999; Palczewski et al., 2000). In consequence, the cytoplasmic concentration of $\mathrm{Ca}^{2+}\left(\left[\mathrm{Ca}^{2+}\right]_{\text {free }}\right)$, which is high (about $600 \mathrm{nM}$ ) in the darkness, drops to a low level $(<50 \mathrm{nM})$. The lowered concentration of calcium ions is the signal for resynthesis of cGMP by guanylyl cyclase (GC), beginning the recovery of the photoreceptor cell to the dark state. The photoreceptor-specific GC, named also retinal GC (retGC), is negatively regulated by $\mathrm{Ca}^{2+}$ (Lolley \& Racz, 1982; Koch \& Stryer, 1988). The enzyme is active below 100 $\mathrm{nM}\left(\left[\mathrm{Ca}^{2+}\right]_{\text {low }}\right)$ and inactive above $500 \mathrm{nM}$ $\left(\left[\mathrm{Ca}^{2+}\right]_{\text {high }}\right)$ concentrations of $\mathrm{Ca}^{2+}$. This $\mathrm{Ca}^{2+}$-dependent activation of retGC is mediated by $\mathrm{Ca}^{2+}$-binding proteins named guanylyl cyclase-activating proteins (GCAPs) and contributes to the recovery of the dark state by photoreceptor cells (Dizhoor et al., 1994; Gorczyca et al., 1994). Three different GCAPs (GCAP1, GCAP2 and GCAP3) have been identified in the vertebrate retina to date (Palczewski et al., 1994; Dizhoor et al., 1995; Gorczyca et al., 1995; Frins et al., 1996; Haeseleer et al., 1999). These highly homologous proteins share structural properties with a larger family of proteins called Neuronal Calcium Sensors (NCS) (Burgoyne \& Weiss 2001).

Although the retina is the primary site where GCAPs are expressed, GCAP1 was also detected in the bovine pineal gland (Venkataraman et al., 2000) and expression of genes encoding GCAP1 and GCAP2 was reported for the chicken pineal gland (Semple-Rowland et al., 1999). Together with the findings that also retGC is present in pineal glands of both species these observations indicate that the synthesis of cGMP in the pineal gland may be regulated in a $\mathrm{Ca}^{2+}$-dependent manner but the physiological significance of this mechanism is unclear.

The aim of our study was to elucidate whether the $19 \mathrm{kDa}$ protein ( $\mathrm{p} 19)$ we had detected in extracts of rat retina and pineal gland using antibodies specific to bovine GCAP1 belongs to the GCAP subfamily. In this report we present data indicating that p19 is most likely a rat ortholog of bovine GCAP1.

\section{MATERIALS AND METHODS}

Chemicals. Acrylamide, bis ( $N, N^{\prime}$-methylene-bis-acrylamide), ammonium persulfate, SDS, TEMED, and Bromophenol Blue were purchased from BioRad Laboratories (Hercules, CA, U.S.A.); GTP, Tris, 2-mercaptoethanol, glycerol, glycine, EDTA, EGTA, phenylmethylsulfonyl fluoride (PMSF), benzamidine, leupeptin, IBMX, dithiothreitol (DTT), $\mathrm{MgCl}_{2}$, and Hepes were purchased from Sigma Chemical Co. (St. Louis, MO, U.S.A.). Neutral alumina (ICN alumina) was purchased from ICN Biomedicals $\mathrm{GmbH}$ (Eschwege, Germany), while CNBr-activated Sepharose 4B from Amersham Pharmacia Biotech AB (Uppsala, Sweden). $\left[\alpha-{ }^{32} \mathrm{P}\right] \mathrm{GTP}$ was purchased from PerkinElmer, Life Sciences (Boston, MA, U.S.A.). Alkaline phosphatase conjugated anti-rabbit IgG and BCIP/NBT color development substrate were purchased from Promega (Madison, WI, U.S.A.).

Antibodies. Monoclonal antibody mAbG2 was generated in BALB/c mice against truncated (GCAP180) bovine GCAP1 (Gorczyca et al., 1995); rabbit polyclonal antibodies pAb23 and pAb850 were raised against recombinant bovine GCAP1 or GCAP2 expressed in E. coli (Gorczyca, 2000).

Animals. Wistar rats 2-3 months old weighing about 180-250 g came from the Institute of Medicine of Work in Eódź. The animals were treated in accordance with procedures approved by the local Ethics Committee For Animal Experimentation in Łódź.

Preparation of rat retinal and pineal gland extracts. Rat retinas and pineal glands were isolated as described by Zawilska et al. (1997). Briefly, the animals were killed in the light phase of a $24 \mathrm{~h}$ lighting cycle (preceded by $0.5 \mathrm{~h}$ adaptation to darkness) by decapita- 
tion and their pineal glands and retinas were quickly isolated under dim red light (intensity about 4 luxes). The obtained organs were then homogenized in water containing inhibitors of proteases (leupeptin, PMSF, benzamidine) using an Ultra Turrax homogenizer. The homogenates were clarified by centrifugations at $30000 \times \mathbf{g}$. The resulting supernatants (the extracts) were collected and used directly in retGC activity assays or in purification procedures as a source of GCAPs. The particulate fraction obtained after the first centrifugation, termed crude retinal (or pineal gland) membranes, was used in GC assays as a source of particulate GCs activity.

Preparation of ROS membranes. Fresh bovine eye balls obtained from a local slaughterhouse were adapted to the darkness and all further procedures were carried out under dim red light at $4^{\circ} \mathrm{C}$. The retinas were dissected within 2-4 h after the death of the animals and rod outer segments (ROS) were isolated using discontinuous sucrose gradient according to McDowell (1993). The obtained ROS pellet was then suspended in $50 \mathrm{mM}$ Hepes, pH 7.8, $10 \mathrm{mM} \mathrm{NaCl}$, homogenized and centrifuged at $30000 \times \boldsymbol{g}$ for $10 \mathrm{~min}$ at $4^{\circ} \mathrm{C}$. The supernatant was discarded and the pellet was washed again under the same conditions. Finally, the pellet was resuspended in the same buffer. The obtained suspension, termed crude ROS membranes or washed ROS (wROS), was used in the retGC activity test.

Purification of p19. The $19 \mathrm{kDa}$ protein was purified from the rat retinal extract by immunoaffinity chromatography according to the modified procedure previously described by Gorczyca (2000) for purification of bovine GCAPs. Briefly, a C10/10 column (Amersham Pharmacia Biotech) containing $2 \mathrm{ml}$ of Sepharose 4B coupled with pAb850 (pAb850Sepharose) against bovine GCAP2 was followed by an identical column containing $2 \mathrm{ml}$ of mAbG2-Sepharose against bovine GCAP1. The extract obtained from 300 rat retinas in a volume of $20 \mathrm{ml}$ was loaded at a flow rate of
$2.0 \mathrm{ml} / \mathrm{h}$ onto the first column and the unbound material was directly loaded onto the second column connected with the first one in tandem. The columns were then washed with $25 \mathrm{mM}$ Tris/HCl, pH 7.5, $50 \mathrm{mM} \mathrm{NaCl}$, disconnected, and washed with $25 \mathrm{mM}$ Tris/ $\mathrm{HCl}, \mathrm{pH}$ 7.5, $0.2 \mathrm{M} \mathrm{NaCl}$ to remove nonspecifically adsorbed proteins. Bound proteins were eluted with $0.1 \mathrm{M}$ glycine, $\mathrm{pH}$ 2.5. Fractions $(1 \mathrm{ml})$ were collected, immediately neutralized with 1.5 M Tris/ $\mathrm{HCl}, \mathrm{pH}$ 8.8, and analyzed for stimulatory effect on GC activity. In some experiments only the mAbG2-Sepharose column was used for p19 purification.

GC activity assay. GC activity was determined in crude membranes (ROS or retinal), prepared as described above and supplemented either with the extracts (retinal or pineal) or with purified p19. The assay used is a modification of the retGC assay described previously (Gorczyca et al., 1995; Gorczyca, 2000). Briefly, $64 \mu \mathrm{l}$ of the final reaction mixture contained $50 \mathrm{mM}$ Hepes, $\mathrm{pH}$ 7.8, $60 \mathrm{mM}$ $\mathrm{KCl}, 10 \mathrm{mM} \mathrm{NaCl}, 10 \mathrm{mM} \mathrm{MgCl} 2,0.5 \mathrm{mM}$ 3-isobutyl-1-methylxanthine (IBMX), $0.4 \mathrm{mM}$ EGTA, $\mathrm{CaCl}_{2}$ in amounts calculated using the computer program "Chelator 1.0" (Schoenmakers et al., 1992) to obtain the desired concentration of $\left[\mathrm{Ca}^{2+}\right]_{\text {free }}, 1 \mathrm{mM}\left[\alpha_{-}{ }^{32} \mathrm{P}\right] \mathrm{GTP}$ (specific activity 30000-50000 d.p.m./ nmole), and crude membranes containing 100 $\mu \mathrm{g}$ of protein, as determined by the BCA Protein Assay (Pierce, Rockford, IL, U.S.A.). The reaction, initiated by adding the membranes, was terminated after $10 \mathrm{~min}$ incubation at $30^{\circ} \mathrm{C}$ by adding $0.4 \mathrm{M} \mathrm{HCl}$. All the above steps were performed at dim red light. The sample was neutralized with $0.2 \mathrm{mM}$ Tris $/ \mathrm{HCl}, \mathrm{pH} 7.4$ and the product ([ $\left.\left.{ }^{32} \mathrm{P}\right] \mathrm{cGMP}\right)$ was separated from the substrate $\left(\left[\alpha-{ }^{32} \mathrm{P}\right] \mathrm{GTP}\right)$ using neutral alumina gel. Finally, the radioactivity of the product was measured using a liquid scintillation counter.

SDS/PAGE and Western blotting. Both extracts (retinal and pineal gland), each containing $30 \mu \mathrm{g}$ of protein as determined by the BCA Protein Assay, were resolved under re- 
ducing conditions in SDS/PAGE using 12.5\% acrylamide gels and electrotransferred onto nitrocellulose (Schleicher \& Schuell, Dassel, Germany) or Immobilon ${ }^{\mathrm{TM}} \mathrm{P}$ membranes (Millipore, Bedhoford, MA, U.S.A.). The membranes were then blocked with $2 \%(\mathrm{w} / \mathrm{v})$ casein and incubated for $1.5 \mathrm{~h}$ with anti-GCAP1 antibodies. After washing with $50 \mathrm{mM}$ Tris, $\mathrm{pH} 7.5,150 \mathrm{mM} \mathrm{NaCl}$ and $0.05 \%$ Tween 20 (TBST) and subsequently three times with 50 $\mathrm{mM}$ Tris, $\mathrm{pH} 7.5,150 \mathrm{mM} \mathrm{NaCl}$ (TBS), the membranes were incubated with anti-rabbit IgG goat antibodies conjugated to alkaline phosphatase and visualized using a NBT/ BCIP-based substrate.

\section{RESULTS AND DISCUSSION}

\section{Antibodies against GCAP1 recognize a 19 $\mathrm{kDa}$ protein in extracts of rat retina and pi- neal gland}

Polyclonal antibody 23 (pAb23), specific to bovine GCAP1, recognizes in rat retinal extract and in rat pineal gland extract a protein with apparent molecular mass of $19 \mathrm{kDa}$

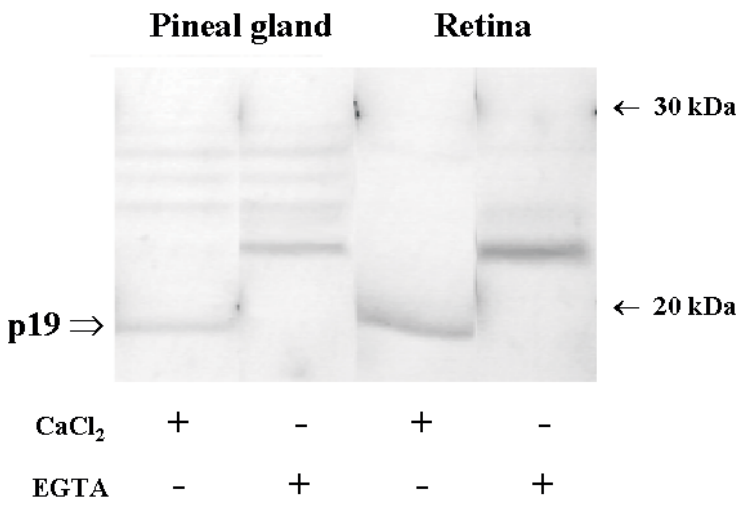

Figure 1. Western blot analysis of rat pineal gland and retinal extracts.

Proteins from each extract (30 $\mu \mathrm{g})$, obtained as described in Materials and Methods, were subjected to SDS/PAGE in the presence of either $1 \mathrm{mM} \mathrm{CaCl}_{2}$ or 1 mM EGTA, electrotransferred onto nitrocellulose membrane and immunostained with antibody (pAb23) against bovine GCAP1. Thin arrows indicate positions of molecular mass standards.
(Fig. 1). In the extract of pineal gland some additional bands of higher molecular mass are weakly immunostained. However, only the 19 $\mathrm{kDa}$ protein displays a characteristic $\mathrm{Ca}^{2+}$ / EGTA-dependent electrophoretic mobility shift and in the presence of EGTA it migrates as a $23 \mathrm{kDa}$ band. Since such a property is typical for GCAPs (Gorczyca et al., 1995; Frins et $a l ., 1996)$, we assume that all other bands are due to unspecific staining. The intensity of p19 staining is weaker in the pineal extract than in the retinal extract indicating that this protein is expressed in the pineal gland at a lower level than in the retina. Our results also support the findings of Cuenca et al. (1998), who using another antibody against bovine GCAP1 have shown by means of immunohistochemical techniques the presence of GCAP1 in the rat retina. Hence, p19 is most likely a rat ortholog of bovine GCAP1.

\section{Retinal and pineal extracts activate retGC in crude ROS membranes}

If $\mathrm{p} 19$ detected in both rat extracts was a GCAP, it should activate in a $\mathrm{Ca}^{2+}$-dependent manner retGC in the ROS membranes. To check this we used the assay of guanylyl cyclase activity. The extracts obtained from the rat retina and from the rat pineal gland markedly (six- and almost three-fold, respectively) stimulate at $\left[\mathrm{Ca}^{2+}\right]_{\text {low }}$ cGMP synthesis in crude membranes of bovine rod outer segments (Fig. 2). In some experiments bovine retinal extract was used as a positive control. Under the same experimental conditions it stimulates the GC activity more than 7-fold (not shown). Neither of the rat extracts stimulate the $\mathrm{GC}$ activity at $\left[\mathrm{Ca}^{2+}\right]_{\text {high }}$ indicating that they indeed activate the retGC and thus display GCAP-like properties. Moreover, the lower potency of the pineal than the retinal extract to activate retGC at $\left[\mathrm{Ca}^{2+}\right]_{\text {low }}$ corresponds to the above observed (Fig. 1) weaker expression of p19 in the pineal gland in comparison with the retina. Since GCAP1 amino acid sequences reveal very high interspecies 


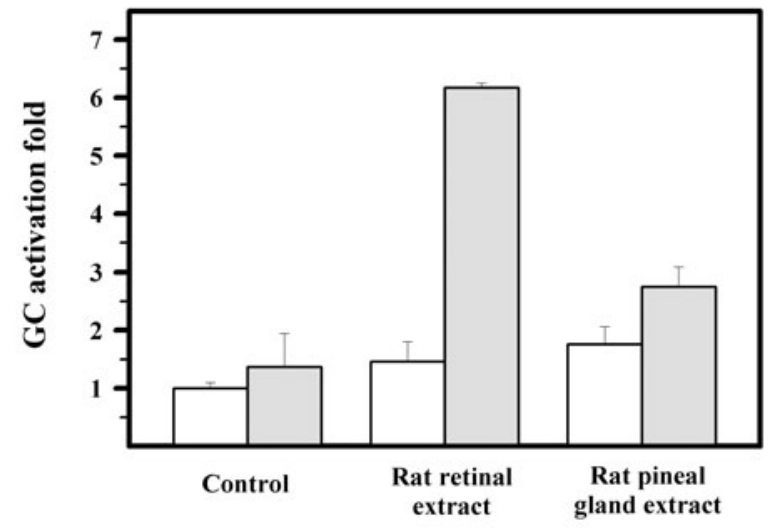

Figure 2. Stimulation of retGC activity by rat retinal and pineal extracts.

The retGC activity was measured in bovine wROS (see Materials and Methods) at $30 \mathrm{nM}$ (filled bars, $\left[\mathrm{Ca}^{2+}\right]_{\text {low }}$ ) and $1 \mu \mathrm{M}$ (open bars, $\left[\mathrm{Ca}^{2+}\right]_{\text {high }}$ ) concentrations of free $\mathrm{Ca}^{2+}$ either in the absence (control) or in the presence of extract (100 $\mu \mathrm{g}$ of protein). The basal activity of retGC, measured at $\left[\mathrm{Ca}^{2+}\right]_{\text {high }}$ in the absence of extracts, was taken as 1.0.

homology (Gorczyca \& Sokal, 2002), in the next step we attempted to isolate $\mathrm{p} 19$ from the rat retinal extract by means of immunoaffinity chromatography using antibodies against bovine GCAP1.

\section{Immunoaffinity purified $\mathbf{p 1 9}$ is recognized by anti-GCAP1 antibodies and activates retGC in crude ROS and retinal membranes}

Specific fractions eluted from the mAbG2-Sepharose column were concentrated, subjected to SDS/PAGE, electrotransferred onto Immobilon ${ }^{\text {TM }} \mathrm{P}$ and either stained using Coomassie Brilliant Blue (CBB) or immunostained with pAb23. In the presence of $\mathrm{CaCl}_{2}$ the very weak band corresponding to the molecular mass of $19 \mathrm{kDa}$ is stained by CBB. There is also strong staining of an unknown protein of about $27 \mathrm{kDa}$. Although the same bands are immunostained by the pAb23 antibody, the intensity of staining is similar for both. Moreover, in the presence of EGTA only p19 exhibits the shift characteristic for GCAPs and migrates as a $22-23 \mathrm{kDa}$ protein (Fig. 3). These results show that $\mathrm{p} 19$, present

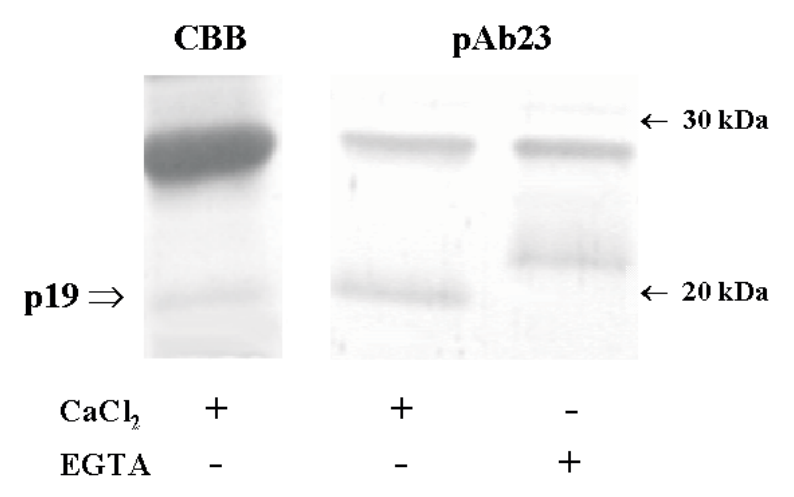

Figure 3. Detection of immunoaffinity purified p19.

Immunoaffinity purified p19 was concentrated, subjected to SDS/PAGE, electrotransferred onto Immobilon $^{\mathrm{TM}} \mathrm{P}$ membrane and then either stained with Coomassie Brilliant Blue R-250 (CBB) or immunostained using pAb23. For CBB staining $40 \mu \mathrm{l}$ of concentrated fraction was loaded onto the gel, while for immunostaining only $10 \mu \mathrm{l}$ was applied. Other details are described in Fig. 1.

in the fractions obtained after immunoaffinity chromatography, displays GCAP1-like properties. The yield of the purification is very low as one can purify only about $9-10 \mu \mathrm{g}$ of p19 from 300 rat retinas.

To check whether the analyzed fractions contain a protein with retGC stimulating activity, they were tested in the GC assay using wROS and crude rat retinal membranes (Fig. 4). Bovine GCAP1 ( $0.2 \mu \mathrm{g}$ of protein), purified from bovine retinal extract in the same way as p19 but without the concentration step, was used as a positive control. It stimulates retGC in wROS about 3-fold. In the presence of $\mathrm{p} 19$, GC activity is elevated at $\left[\mathrm{Ca}^{2+}\right]_{\text {low }}$ by a factor of 1.8 in bovine wROS and by a factor of 1.4 in crude rat retinal membranes. At the same time there is no stimulation of GC activity by p19 at $\left[\mathrm{Ca}^{2+}\right]_{\text {high }}$ in both membrane fractions. These results provide further evidence that the analyzed fractions contain GCAP. The lower stimulatory potency of $\mathrm{p} 19$ in comparison with bovine GCAP 1 may be a result of $\mathrm{p} 19$ inactivation during isolation. Interestingly, the fractions obtained after immunoaffinity chromatography of rat retinal extract on 


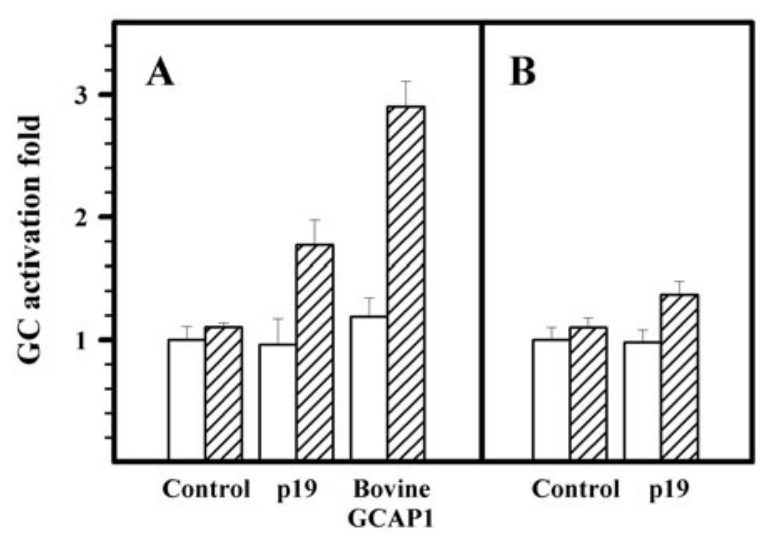

Figure 4. Stimulation of retGC activity by p19.

The retGC activity was measured at $\left[\mathrm{Ca}^{2+}\right]_{\text {low }}$ (filled bars) or $\left[\mathrm{Ca}^{2+}\right]_{\text {high }}$ (open bars) in bovine wROS (A) or in crude rat retinal membranes (B) either in the absence (control) or in the presence of immunoaffinity purified p19 (0.2 $\mu \mathrm{g}$ of protein). Immunoaffinity purified bovine GCAP1 ( $0.2 \mu \mathrm{g}$ of protein) was used as a positive control. All other details are described in Fig. 2.

pAb850-Sepharose do not contain any GCAPlike activity, although the pAb850 antibody was able to stain a band corresponding to molecular mass of about $21 \mathrm{kDa}$ in both the retinal and pineal rat extracts (not shown). On the basis of all the above results one can assume that p19 is a rat ortholog of bovine GCAP1 but further studies are required to prove it definitively.

In the retinal photoreceptor cells the role of GCAP1 as a key element in the phototransduction is well established (recently reviewed by Gorczyca \& Sokal, 2002). Although the presence of GCAP1 was also proved in the chicken (Semple-Rowland et al., 1999) and bovine (Venkataraman et al., 2000) pineal glands, its physiological role there is still elusive. It is only hypothesized that since pinealocytes contain most of the retinal proteins characteristic for phototransduction and the pineal bodies of lower vertebrates and newborn mammals directly respond to light (Falcon, 1999; Meissl, 1997; Tosini et al., 2000), this $\mathrm{Ca}^{2+}$-dependent regulation of retGC in the gland might be a part of a phototransduction process. In mammals, during their maturation, the direct light sensitivity of the pineal gland disappears and it is suggested that the elements of the phototransduction machinery are either no longer expressed or are adopted by other signaling systems. GCAP1 and retGC are still present in bovine pineal glands isolated from mature animals and it is postulated that the $\mathrm{Ca}^{2+}$-dependent regulation of cGMP synthesis in the pineal gland is linked to $\alpha$-adrenergic signaling through regulation of $\left[\mathrm{Ca}^{2+}\right]_{\text {free }}$ by the $\alpha_{2 \mathrm{D} / \mathrm{A}^{-a} \text {-adrenergic receptor (Venkataraman et }}$ al., 1998; 2000).

In summary, our results show that $\mathrm{p} 19$, recognized in the rat retinal and pineal extracts by an antibody specific to bovine GCAP1, belongs to the family of guanylyl cyclase-activating proteins (GCAPs). They also indicate that $\mathrm{p} 19$ is most likely a rat ortholog of bovine GCAP1 thus supporting observations of others, extending them to new species, and suggesting that $\mathrm{Ca}^{2+} / \mathrm{GCAP} 1 /$ retGC signaling in pineal gland is well conserved in evolution. What is the physiological role of this signaling pathway in the pineal gland remains an open question.

\section{R E F E R E N C E S}

Burgoyne RD, Weiss JL. (2001) The neuronal calcium sensor family of $\mathrm{Ca}^{2+}$-binding proteins. Biochem J.; 353: 1-12.

Cuenca N, Lopez S, Howes K, Kolb H. (1998) The localization of guanylyl-cyclase-activating proteins in the mammalian retina. Invest Ophthalmol Vis Sci.; 39: 1243-50.

Dizhoor AM, Lowe DG, Olshevskaya EV, Laura RP, Hurley JB. (1994) The human photoreceptor membrane guanylyl cyclase, RetGC, is present in outer segments and is regulated by calcium and a soluble activator. Neuron.; 12: 1345-52.

Dizhoor AM, Olshevskaya EV, Henzel WJ, Wong S, Stults JT, Ankoudinova I, Hurley JM. (1995) Cloning, sequencing, and expressing of a $24-\mathrm{kDa} \mathrm{Ca}{ }^{2+}$-binding protein activating 
photoreceptor guanylyl cyclase. J Biol Chem.; 270: 25200-6.

Falcon J. (1999) Cellular circadian clocks in the pineal. Progr Neurobiol.; 58: 121-62.

Frins S, Bönigk W, Müller F, Kellner R, Koch KW. (1996) Functional characterization of a guanylyl cyclase-activating protein from vertebrate rods. J Biol Chem.; 271: 8022-7.

Gorczyca WA. (1999) Role of calcium ions in vertebrate phototransduction. $\mathrm{Pol} J$ Pharmacol.; 51: 167-72.

Gorczyca WA. (2000) Use of nucleoside $\alpha$-phosphorothioates in studies of photoreceptor guanylyl cyclase: purification of guanylyl cyclase-activating proteins. Methods Enzymol.; 315: 689-707.

Gorczyca WA, Sokal I. (2002) GCAPs: $\mathrm{Ca}^{2+}$-sensitive regulators of retGC. In: Photoreceptors and calcium. Baehr W, Palczewski K, edn, Kluwer Academic Publishers (in press).

Gorczyca WA, Gray-Keller MP, Detwiler PB, Palczewski K. (1994) Purification and physiological evaluation of guanylate cyclase activating protein from retinal rods. Proc Natl Acad Sci U S A.; 91: 4014-18.

Gorczyca WA, Polans AS, Surgucheva I, Subbaraya I, Baehr W, Palczewski K. (1995) Guanylyl cyclase-activating protein: a calcium-sensitive regulator of phototransduction. J Biol Chem.; 270: 22029-36.

Haeseleer F, Sokal I, Li N, Pettenati M, Rao N, Bronson D, Wechter R, Baehr W, Palczewski K. (1999) Molecular characterization of a third member of the guanylyl cyclase-activating protein subfamily. J Biol Chem.; 274: 6526-35.

Koch K-W, Stryer L. (1988) Highly cooperative feedback control of retinal rod guanylate cyclase by calcium ions. Nature.; 334: 64-6.

Lolley RN, Racz E. (1982) Calcium modulation of cyclic GMP synthesis in rat visual cells. $\mathrm{Vi}$ sion Res.; 22: 1481-86.

McDowell JH. (1993) Preparing rod outer segment membranes, regenerating rhodopsin, and determining rhodopsin concentration. Methods Neurosci.; 15: 23-30.
Meissl H. (1997) Photic regulation of pineal function. Analogies between retinal and pineal photoreception. Biol Cell.; 89: 549-54.

Palczewski K, Subbaraya I, Gorczyca WA, Helekar BS, Ruiz CC, Ohguro H, Huang J, Zhao X, Crabb JW, Johnson RS, Walsh KA, Gray-Keller MP, Detwiler PB, Baehr W. (1994) Molecular cloning and characterization of retinal guanylyl cyclase-activating protein. Neuron.; 13: 395-404.

Palczewski K, Polans AS, Baehr W, Ames JB. (2000) $\mathrm{Ca}^{2+}$-binding proteins in the retina: structure, function, and the etiology of human visual diseases. BioEssays.; 22: 337-50.

Schoenmakers TJ, Visser GJ, Flik G, Theuvenet AP. (1992) CHELATOR: an improved method for computing metal ion concentrations in physiological solutions. Biotechniques.; 12: 870-9.

Semple-Rowland SL, Larkin P, Bronson JD, Nykamp K, Streit WJ, Baehr W. (1999) Characterization of the chicken GCAP gene array and analyses of GCAP1, GCAP2, and GC1 gene expression in normal and $r d$ chicken pineal. Mol. Vis.; 5: 14.

Tosini G, Doyle S, Geusz M, Menaker M. (2000) Induction of photosensitivity in neonatal rat pineal gland. Proc Natl Acad Sci U S A.; 97: 11540-4.

Venkataraman V, Duda T, Sharma RK. (1998)

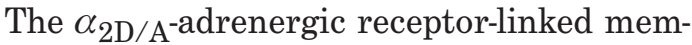
brane guanylate cyclase: a new signal transduction system in the pineal gland. FEBS Lett.; 427: 69-73.

Venkataraman V, Nagele R, Duda T, Sharma RK. (2000) Rod outer segment membrane guanylate cyclase type 1-linked stimulatory and inhibitory calcium signaling systems in the pineal gland: biochemical, molecular, and immunohistochemical evidence. Biochemistry.; 39: 6042-52.

Zawilska JB, Rosiak J, Senderecka M, Nowak JZ. (1997) Suppresive effect of NMDA receptor antagonist MK-801 on nocturnal seroto$\operatorname{nin} N$-acetyltransferase activity in the rat pineal gland. Pol J Pharmacol.; 49: 479-83. 